\title{
“SEMPRE FUI MEIO TERMO": A CLÍNICA FONOAUDIOLÓGICA E A CONSTRUÇÃO DE NARRATIVAS NO CONTEXTO DA EDUCAÇÃO SUPERIOR
}

\author{
"SIEMPRE FUÍ MEDIANO": LA CLÍNICA DE TERAPIA DEL LENGUAJE Y LA \\ CONSTRUCCIÓN DE NARRATIVAS EN EL CONTEXTO DE LA EDUCACIÓN \\ SUPERIOR
}

\section{“I'VE ALWAYS BEEN KIND OF AVERAGE": SPEECH THERAPY AND NARRATIVE CONSTRUCTION IN HIGHER EDUCATION}

\author{
Lais Oliva DONIDA ${ }^{1}$ \\ Alexandre BERGAMO ${ }^{2}$ \\ Sandra MAIA-VASCONCELOS ${ }^{3}$
}

RESUMO: O objetivo deste artigo é discutir tanto a narrativa produzida no contexto da Educação Superior quanto o lugar da clínica fonoaudiológica no acolhimento de universitários com dificuldades acadêmicas. Para tanto, foram utilizadas entrevistas e parte do material escrito produzido por um universitário que procurou a clínica fonoaudiológica com o objetivo de diagnosticar e corrigir as dificuldades. A discussão do caso mobilizou três áreas: Linguística; Sociologia; e Fonoaudiologia. A procura por tratamento representa, nesse contexto, uma possibilidade também de atribuir sentido à sua história de vida. A atribuição de um diagnóstico para suas dificuldades educacionais faz com que o espaço clínico emerja como lugar de acolhimento e apoio que a Universidade não consegue ser.

PALAVRAS-CHAVE: Dificuldade. Narrativa. Universidade.

RESUMEN: El objetivo de este artículo es discutir tanto la narrativa producida en el contexto de la Educación Superior, como el lugar de la clínica fonoaudiológica en la acogida de estudiantes universitarios con dificultades académicas. Para ello, se utilizaron entrevistas y parte del material escrito producido por un estudiante universitario que buscó la clínica de fonoaudiología para diagnosticar y corregir las dificultades. La discusión del caso movilizó tres áreas: lingüística, sociología y Fonoaudiología. La búsqueda de una clínica fonoaudiológica, en este contexto, no se lleva a cabo al azar por el estudiante: marca un lugar que asume la posibilidad de ser responsable de la "cohesión" de la historia de vida del estudiante. Al tener el "poder" de "nombrar" estas dificultades educativas, que se extienden a todos los demás aspectos de su vida, la clínica emerge como el lugar de apoyo y acogida que

\footnotetext{
${ }^{1}$ Universidade Federal de Santa Catarina (UFSC), Florianópolis - SC - Brasil. Doutoranda no programa de Pósgraduação em Linguística. ORCID: https://orcid.org/0000-0003-3508-7030. E-mail: lais.donida@gmail.com

${ }^{2}$ Universidade Federal de Santa Catarina (UFSC), Florianópolis - SC - Brasil. Professor no Departamento de Sociologia e Ciência Política. Doutorado em Sociologia (USP). ORCID: https://orcid.org/0000-0002-1058-7381. E-mail: a bergamo@hotmail.com

3 Universidade Federal do Ceará (UFC), Fortaleza - CE - Brasil. Docente no Departamento de Letras Vernáculas e no Programa de Pós-Graduação em Linguística. Doutorado em Ciências da Educação pela Universidade de Nantes (UN) - França. ORCID: https://orcid.org/0000-0001-7201-6173. E-mail: sandramaiafv@gmail.com
} 
acciones educativas llevadas a cabo por la institución o las clases privadas para minimizar los déficits de alfabetización no podrían hacer.

\section{PALABRAS CLAVE: Dificultad. Relato. Universidad}

ABSTRACT: The purpose of this paper is to discuss both the narrative produced in the context of Higher Education and the place of the speech therapy clinic in welcoming university students with academic difficulties. For this purpose, interviews and part of material written by an university student that searched for the speech therapy clinic with the objective of diagnosing and correcting difficulties were used. The case discussion mobilized three areas: Linguistics, Sociology and Speech Therapy. The search for the speech therapy clinic, in this context, is not done randomly by the student: it also represents a possibility of attributing sense to his life story. The attribution of a diagnostic to his learning difficulties makes the clinic space emerge as a harboring place of support that the university cannot be.

KEYWORDS: Difficulty. Narrative. University

\section{Introdução}

As pesquisas que se debruçam sobre a análise das narrativas autobiográficas são recentes nas áreas da Linguística e da Fonoaudiologia, mas já há muito estudadas pela Sociologia. Na Linguística, a autobiografia esteve condicionada à definição da tipologia textual/discursiva, descrição e adequação gramatical, reduzindo-a a um objeto rígido (geralmente uma produção escrita) e passível de análise formal. Contudo, essa delimitação se mostrou pouco aplicável, uma vez que a materialização linguística, quer seja em produções orais ou escritas, não compreendiam os aspectos sociais e históricos que situam a emergência de autobiografias em diversos contextos, através de diversas tipologias textuais/discursivas, carregadas de elementos subjetivos (VASCONCELOS; CARDOSO, 2009).

A clínica fonoaudiológica, por sua vez, historicamente se consolidou como um lugar de remediação de alterações cognitivo-linguísticas, ou seja, ela incumbiu-se do papel social de confirmação, caracterização e posterior remediação de alterações "patológicas" em nossa sociedade (ELIASSEN, 2018). O fonoaudiólogo deve estar atento às narrativas de sofrimento contadas, mas, além disso, cauteloso no momento da avaliação, pois os relatos de dificuldades, em consonância com afirmações de outros profissionais, podem induzir o fonoaudiólogo pouco atento a diagnósticos equivocados.

É nesse contexto que emerge a Entrevista Clínica (EC) (MAIA-VASCONCELOS, 2005). A abordagem aqui adotada, EC, contrapõe-se à anamnese, a qual é composta de uma lista de aspectos gerais a serem considerados para o direcionamento da avaliação e acredita-se 
que deve haver a mínima influência do terapeuta na condução do caso, isso porque o pesquisador se sente implicado no seu objeto de estudo e não distanciado, como é comum se perceber nas ciências exatas e da saúde. $\mathrm{O}$ aspecto clínico em narrativa de vida vislumbra o caráter de uma distinção entre experiência e vivência: o sujeito que chega ao consultório traz sua vivência, ao passo que o profissional recebe sua narrativa como experiência. A distinção se dá pelo vivido e pelo experienciado dos sujeitos (MAIA-VASCONCELOS, et al., 2013).

Com isso, há uma tentativa de afastamento da clínica fonoaudiológica em busca de alterações e uma nova perspectiva de trabalho emerge: a investigação acerca da construção de diagnósticos e dificuldades educacionais e sociais que chegam ao contexto clínico veladas por "camadas" de histórias de fracasso e sofrimento perante as instituições educacionais e interações sociais que envolvam práticas da língua(gem), principalmente a escrita (DONIDA, 2018). A narrativa de vida torna-se, portanto, um elemento essencial a ser considerado na EC, pois possibilita compreensões acerca da definição do caráter da própria prática profissional: acompanhamento clínico; acolhimento; encaminhamento a outros profissionais; contatos interdisciplinares etc. Assim, para compreender como se dá a construção de dificuldades que necessitam de remediação clínica, torna-se necessário investigar com cautela como se dá a construção dessas "narrativas de dificuldades" durante a EC.

Há muitas pesquisas voltadas à discussão entre a relação de sofrimento perante a linguagem escrita em crianças e adolescentes e a transformação de características inerentes à diversidade humana e/ou marcas da desigualdade social em alterações de cunho patológico, tanto no contexto da clínica fonoaudiológica quanto nas instituições educacionais (SIGNOR; BERBERIAN; SANTANA, 2017; GIROTO; ARAÚJO; VITTA, 2019; COLOMBANI; CARÁCIO; VERÍSSIMO, 2019). Contudo, na Educação Superior essa temática ainda é pouco explorada (DONIDA, 2018) ${ }^{4}$.

A construção de narrativas que envolvem dificuldades acadêmicas é um processo contínuo que perpassa experiências anteriores e simultâneas ao ingresso na Universidade, mas é nesse espaço que, aparentemente, elas tomam "forma". Há, com isso, um conjunto de fatores que se entrelaçam após o ingresso na Educação Superior no sentido de formalizar um “encaminhamento clínico" (DONIDA, 2018).

\footnotetext{
${ }^{4}$ Não será realizada uma discussão extensa acerca da transformação de fatores de ordem social, histórica, cultural e econômica em diagnósticos e problemas clínico-biológicos que requerem a utilização de medicamentos e o/ou intervenções terapêuticas - o que convencionalmente vem sendo denominado de "medicalização" e "patologização". Para mais detalhes e aprofundamento teórico, o leitor poderá consultar as seguintes bibliografias: "La psiquiatrización de la vida cotidiana: el DSM y sus dificultades" de autoria de Sandra Caponi (2018) e "Novas capturas, antigos diagnósticos da era dos transtornos", de Cecília A. Lima Collares, Maria Aparecida Affonso Moysés e Monica C. França Ribeiro (2013).
} 
A partir do exposto, o objetivo deste artigo é discutir tanto a narrativa produzida no contexto da Educação Superior quanto o lugar da clínica fonoaudiológica no acolhimento de universitários com dificuldades acadêmicas. Para tanto, serão utilizadas entrevistas e parte do material escrito produzido por Gabriel ${ }^{5}$, que procurou a clínica fonoaudiológica com o objetivo de diagnosticar e corrigir as dificuldades que, segundo ele, o acompanham desde a infância.

Para tanto, a análise exige a colaboração de três diferentes áreas e problemáticas de pesquisa. Primeiro, uma avaliação das condições e competências linguísticas do caso em discussão: a presença ou ausência de dificuldades específicas de escrita e de leitura; a familiaridade com certos gêneros discursivos, notadamente os de uso corrente no contexto escolar e universitário; se há ou não progresso na compreensão desses gêneros quando trabalhados na clínica. Segundo uma análise da história e da trajetória familiares em função de condicionantes sociais implicados nas chances de mobilidade social; das formas de percepção dessa trajetória; da interferência dos mecanismos de dominação simbólica implicados; das relações de gênero. Terceiro, uma análise das condições de produção de uma autonarrativa: a presença de certos marcadores sociais e simbólicos; as estratégias linguísticas para a construção do sentido.

A partir disso, busca-se apresentar ao leitor de que maneira essas três áreas e problemáticas de pesquisa podem colaborar entre si na construção conjunta da análise do caso de um estudante da Educação Superior com dificuldades acadêmicas. O artigo que segue representa esse esforço, ainda que de forma inicial, de diálogo e articulação entre esses três campos do conhecimento.

\section{Apresentação do Caso: Gabriel, o "meio termo"}

Gabriel, no momento da pesquisa, tinha 42 anos e residia em São José (SC) com a esposa e as duas filhas. Graduado em Cinema há mais ou menos 15 anos em uma faculdade particular, decidiu retomar os estudos na área de Ciências Agrárias, curso de Zootecnia, em uma Universidade Federal. No momento em que o encontramos, devido às dificuldades

\footnotetext{
${ }^{5} \mathrm{O}$ nome utilizado aqui é fictício, assim como serão omitidas informações que possam identificar o participante ou outra pessoa citada durante a análise dos dados. O participante assinou o Termo de Consentimento Livre e Esclarecido (TCLE), que se insere no Projeto de Pesquisa "A Diversidade nas Formas de Transmissão Cultural: reflexões a partir do acesso à cultura escrita de estudantes universitários com dificuldades de leitura e escrita" sob o Comitê de Ética $n^{0}$ 55663716.7.0000.0121, da Universidade Federal de Santa Catarina. Para maiores detalhes sobre o caso, ele pode ser lido na íntegra no trabalho de Donida (2018): "Dificuldades de Leitura e Escrita em Universitários: Desvelando discursos".
} 
acadêmicas e pessoais, havia optado por trancar sua matrícula na instituição. Ele trabalhava como supervisor em uma instituição prisional, tendo atuado anteriormente como adestrador de cães. Sua esposa é natural de uma cidade localizada no norte do Paraná, não possui Ensino Médio completo e é dona de um salão de beleza em que atua como cabeleireira. $\mathrm{O}$ casal tem duas filhas de seis e quatro anos de idade matriculadas na Educação Infantil, na rede municipal.

Quanto à família, seu pai era militar e faleceu quando Gabriel tinha 11 anos. Segundo ele, o pai "trabalhava dia e noite", era muito "durão" e "brigava" quando ele respondia errado as perguntas que lhe fazia sobre os conteúdos escolares. A mãe, por sua vez, cuidava do lar e ajudava nas atividades escolares. Possui seis irmãos, mas afirma que quase não teve contato com eles, pois é o caçula. Também menciona que os irmãos eram todos “inteligentes" e não tiveram dificuldades escolares. Gabriel não se recorda de ter visto nem a mãe, nem os irmãos lendo ou escrevendo.

Após o falecimento do pai, Gabriel passou a estudar em uma escola pública, abandonando os estudos na $4^{\text {a }}$ série do Ensino Fundamental. Afirma que sua desistência se deveu à desmotivação frente aos estudos e à falta de uma "base" de conhecimentos que fez com que "empurrasse com a barriga" a escolarização, já que tinha muitas dificuldades e, por isso, "não aprendia". Durante toda sua trajetória escolar, afirma nunca ter lido ou escrito, apenas realizava atividades obrigatórias que a escola exigia. Mencionou que realizava leituras de gibis durante sua infância e que seu dia a dia, nessa época, envolvia assistir televisão, cuidar dos animais que havia em sua casa ou brincar sozinho.

Retornou à escola muitos anos depois para fazer o curso de Educação de Jovens e Adultos (EJA), concluindo por volta dos 18 anos de idade. Dois anos depois, ingressou no curso de Cinema em uma faculdade particular. Quanto ao atual curso na Universidade, ressalta que ingressou como "retorno de graduado", pois não teria condições de passar no vestibular. O estudante menciona que as dificuldades são mais perceptíveis nesse momento da sua vida: não consegue elaborar um texto, lhe faltam ideias, informações, argumentos para iniciar o assunto, "trava", não compreende as questões das provas. Gabriel comenta que conseguiu, no máximo, escrever em torno de 15 a 20 linhas com suas próprias ideias, nunca além disso. Ademais, diz que sua letra é "muito feia" e, por isso, tem vergonha de escrever no papel para as outras pessoas.

Mesmo pagando professores particulares para reforço acadêmico em disciplinas como Química e Matemática, Gabriel menciona que, na graduação, consegue entender o conteúdo, mas não o desenvolver no momento da avaliação. Várias provas, inclusive, chegaram a ser 
entregues sem responder a nenhuma questão, pois não compreendia o enunciado, principalmente quando as perguntas eram "muito grandes e complexas". Mas, segundo conta, há professores que permitem a utilização de materiais para a resolução das provas, o que faz com que tire notas melhores. Diz também ter dificuldade com trabalhos que necessitem da utilização de recursos digitais, tais como formatação de textos, planilhas, pesquisas etc., bem como com diversos gêneros acadêmicos, pois nunca os escreveu.

Atualmente, em seu trabalho como supervisor, diz se sentir muito inseguro quanto à escrita, já que precisa escrever relatórios (chamados de relatórios de Comunicação Interna CI). Também estava estudando por conta própria para prestar concurso público, uma vez que ele e a esposa querem "melhorar de vida".

Gabriel procurou a Clínica Escola de Fonoaudiologia ao receber um e-mail institucional sobre um projeto de atendimento a universitários com dificuldades de leitura e escrita. Após avaliação inicial, observou-se que Gabriel apresentava dificuldade para iniciar a escrita de gêneros diversos, dificuldade de coesão, coerência, ortografia, desconhecimento sobre a estrutura de alguns gêneros, termos técnicos e/ou palavras pouco frequentes em seu cotidiano, dificuldade com o traçado da letra e em realizar inferências. Gabriel referiu ter muito cansaço e desânimo nas atividades.

Ao ser convidado para participar de uma oficina de práticas de letramentos para universitários, preferiu atendimento individual, mencionando sentir-se constrangido de expor suas dificuldades. Ao iniciar acompanhamento fonoaudiológico, porém, apresentou pouca frequência e aderência às terapias semanais, as quais foram continuadas quinzenalmente por insistência do estudante durante quase dois anos.

É necessário ressaltar que a prática fonoaudiológica orientou-se a partir da perspectiva enunciativo-discursiva, a qual concebe a interação dos sujeitos como dialógica, em constante troca mediada e constituída pela linguagem. Com isso, terapeuta e participante são considerados em sua condição histórica e social e só existem a partir do lugar que ocupam na interação. Compreendendo-se também que a interação é sempre concretizada por meio de gêneros discursivos, ou seja, formas relativamente estáveis de enunciados, de acordo com a perspectiva de Bakhtin e seu Círculo (2003). Assim, a própria Entrevista Clínica conceitua-se como um gênero discursivo, em que se espera que o terapeuta ocupe determinado lugar, atuando de determinada forma, enquanto o participante relata seu sofrimento para aquele que o escuta (SANTANA; SANTOS, 2017).

As interações, portanto, são sempre realizadas a partir da inter-relação entre aspectos sociais e intersubjetivos, que emergem em signos linguísticos (palavras não neutras), dotadas 
de sentido e de ideologia (formas de ver o mundo). Nessa perspectiva, os interactantes são (re)conhecidos como seres incompletos que, através das trocas dialógicas, buscam sua completude um no outro. Também se consideram os participantes como únicos e singulares, assim como o momento da interação, que nunca se repete (BAKHTIN, VOLOSHÍNOV, 2014).

Do mesmo modo, as sessões terapêuticas foram animadas através de práticas de leitura e escrita mediadas por gêneros como poesia, música, resumos, narrativas pessoais, os quais também compuseram o corpus de registros para análise deste artigo.

\section{"Vou mostrar o quanto sou limitado": contexto de produção da narrativa}

A frase escrita acima foi utilizada por Gabriel para dar início a uma narrativa escrita que ele fez sobre suas dificuldades. Em parte, ela se explica pelo seu próprio contexto de produção: a busca por auxílio na Clínica de Fonoaudiologia. Portanto, sua narrativa é organizada de forma a dar coerência e justificar a procura pelo atendimento. A partir de agora, serão apresentados excertos da Entrevista Clínica de Gabriel, identificado como “G”, em diálogo com a pesquisadora "P".

G: Eu nunca fui bom em futebol, nunca fui bom em soltar pipa, nunca fui bom em andar de bicicleta, sempre fui meio termo...

$P$ : Você é o caçula da família?

G: Sim, sou o caçula. Mas sempre fui o meio termo...Eu nunca fui melhor para isso do que para aquilo, sempre fui meio termo.

A narrativa representa um esforço de sistematização de eventos que resulta também numa "essencialização", a exemplo do que Pierre Bourdieu (2008) fala dos "atos de nomeação", ainda que não possa lhe ser atribuído um "nome". Como será pontuado mais adiante, essa "essencialização" ficará completa quando ele, finalmente, conseguir lhe atribuir um "nome". Nesse processo, passado e presente são unificados por meio de uma "essência" que os atravessa. E não se trata de uma "essência" qualquer, mas uma que ocupa um lugar social específico, ou que lhe confere um lugar social específico, distante daquilo que se espera e designa como "normalidade".

O contexto em que a narrativa é produzida - clínico, de acolhimento de uma dificuldade - não apenas propicia que ela seja elaborada dessa forma, como inclusive demanda que ela seja assim. E, além disso, como Jerome Bruner (1997) já havia chamado a atenção, as pessoas fazem uso da "narrativa" sempre que sentem necessidade de "definirem" a si próprias. 
Embora a narrativa de Gabriel seja estruturada dessa forma porque seu contexto de produção, a clínica, assim exige, não se trata de uma narrativa "inventada", e sim de um "noema de recordação" (ROSENTHAL, 2014) ${ }^{6}$. Ou seja, a narrativa é organizada com base em um tema específico: suas dificuldades de aprendizagem. Os personagens (familiares, amigos, professores) e episódios citados são mobilizados de forma a produzir uma narrativa coesa e coerente com o contexto em questão. Sendo assim, ela tem início no período da alfabetização, e não há maiores menções a outras informações a respeito de seus familiares, a não ser aquelas que ele supõe serem coerentes com sua narrativa.

A participação de seu pai e sua mãe em sua narrativa de vida, por exemplo, reproduzem uma relação de gênero bastante desigual e hierarquizada. Embora a mãe seja a figura mais presente em sua trajetória escolar, é o pai quem decide os rumos dessa trajetória:

G: Eu lembro que quando eu ia para a primeira série, se eu não me engano é isso tá? Se não me engano era a primeira série, meu pai disse "não, não tem condições de ir para primeira série"; Eu tinha passado e ele foi lá na escola e disse que não tinha condições de passar. Ele falou "não". A gente acompanhava um pouco, né? Minha mãe, tal...Mais minha mãe... E acabei tendo que repetir a primeira série porque não tinha condições, sabe? [...] Mas o meu pai, mas meu pai não era muito não... meu pai era militar e ele trabalhava muito, trabalhava dia e noite então era mais complicado, ele era meio durão na hora de ensinar alguma coisa já, assim... Já me travava também, porque ele é muito bravo e se eu não conseguir ele já brigava, então isso também... [...] eu lembro que ele era muito bravo então a gente tinha medo até de responder porque se responder errado ele brigava e tal...

$P$ : E a sua mãe, como é que era?

G: Com a minha mãe já era um pouco melhor, sabe? Já era melhor, já não era tanto assim...

Ainda que a menção às figuras paterna e materna sejam circunstanciais, chama a atenção que essa relação de gênero, desigual e hierarquizada, reproduz-se em outros contextos, seja na relação de Gabriel com a escola e a carreira profissional, seja na relação com as filhas que estão neste momento em idade escolar. Bernard Lahire (2002) já havia mencionado a desigual participação de homens e mulheres na educação dos filhos e como a educação é, para muitas famílias, tarefa feminina. Isso não implica, entretanto, que elas tenham algum poder de decisão sobre a conduta a ser adotada diante de um problema com o filho. Para alguns desses filhos homens, o amadurecimento vem acompanhado de uma

${ }^{6}$ Três questões estão aqui implicadas: primeiro que a sequência da vivência e a sequência da recordação são diferentes. Segundo que o ato de se voltar para o passado implica uma seleção de vivências da memória que se apresenta diferentemente em função da perspectiva do presente. E, terceiro, a diferença entre recordação e narração: esta molda aquela adaptando-a às convenções linguísticas e sociais (ROSENTHAL, 2014). 
aproximação da figura do pai e um distanciamento da mãe e, consequentemente, da escolarização.

Neste caso, vê-se que Gabriel seguidamente desiste da escola e, posteriormente, da Universidade, ora em função de suas dificuldades, ora por questões de trabalho, mostrando que muitas vezes a escolarização está em segundo plano. Mas ao se explorar o fato de que se distanciar da mãe implica distanciar-se da escola, abre-se um paradoxo temporal que caberia relembrar, ainda que brevemente. Segundo a perspectiva de Rousseau (1966), a educação seria uma tarefa de homens dirigida a homens. A escolarização de mulheres é uma atividade bem recente na história da humanidade, atividade que levou muitas escritoras a assumir pseudônimos masculinos para poderem lançar suas obras ou terem lugar na sociedade. Este é um tema que foi tratado também na literatura, com o célebre romance Grandes Sertões: Veredas, de Guimarães Rosa (2006). O limite entre os poderes paterno e materno para Gabriel parece ultrapassar a figuração do ser homem ou ser mulher. Há o fator poder imbricado na figura do pai que se duplica pela imagem de militar, de alguém que intimida por ser o pai e o poder na rua também. Toda forma de poder causa medo e inveja, e todo oprimido tudo faz para garantir-se em permanente opressão (FREIRE, 1977).

Sergio Miceli (2001) mostra como, no caso da geração de escritores pré-modernistas brasileiros, os caçulas recebiam um menor investimento na transmissão do capital social familiar, ainda mais aqueles que tinham perdido o pai ainda pequenos, e, diante disso, dirigiam-se às carreiras consideradas mais "femininas", ou seja, aquelas ligadas à cultura e à arte. Ainda que não estejamos falando de uma fração da elite intelectual, como no caso de Miceli (2001), é importante mostrar como Gabriel gravita em um campo de relações - em termos de gênero - semelhante: à exemplo do pai, sonha com uma "carreira militar", mas se torna supervisor em uma instituição prisional desenvolvendo um trabalho burocrático, por isso, continua prestando concurso para ser policial. E o primeiro curso universitário que fez, mas que não tentou seguir profissionalmente, foi "Cinema". Na verdade, sua relação com o Cinema jamais foi "profissional", apenas de "entretenimento", e menciona seu gosto por um gênero bastante específico de dramaturgia: a telenovela.

\section{$P:$ E em casa eles [os irmãos] ajudavam?}

G: Não, meus irmãos não... cada um tinha sua vida, eu tinha 11 anos, meu pai morreu, ai mudou toda nossa vida, ficou totalmente... [...] Com 11 anos meu pai morreu, eu acho que foi com 13 anos que eu fui para escola pública... ai acho que foi na quarta série, se não me engano, quando eu fui para pública eu acho... que foi na quarta série e dai ali para frente as coisas não foram bem... ai eu acho que eu parei dois anos ou um ano de estudar... 
depois eu fui fazer supletivo, e depois de muitos anos eu fui fazer Faculdade de Cinema, pelo vestibular.

[...]

G: Televisão assistia bastante, quando era pequeno tinha uns brinquedos que eram Playmobil e aquilo era minha diversão, para mim aquilo era tudo, brincava o tempo inteiro, já tava começando a ficar adolescente e foi quando eu larguei, mas na minha infância era aquilo direto. [...] Eu saía muito pouco, nunca sai muito, teve uma fase que eu sai muito, mas foi um pouco maior, pequeno sempre fiquei muito em casa... meus irmãos não, tem um irmão com dois anos de diferença e ele sempre saía muito com amigos $e$ etc.

Além disso, conforme pontua Rosenthal (2014, p. 232), “[...] falar sobre lembranças se constitui, em cada caso, pelos enquadramentos interativamente negociados e produzidos na ação prática e pelas modificações desses enquadramentos que ocorrem repetidamente no transcurso da interação". Assim, por se tratar de um contexto clínico, em que o "responsável" pelo "registro" dessa narrativa ocupa o papel de pesquisador, mas também de alguém cuja preocupação é direcionada para uma possível "intervenção", o "registro" também merece ser estudado com cautela.

O "registro" principal torna-se aquilo que precisa ser "corrigido", a exemplo do que Peter Burke (1995) fala a respeito dos registros dos processos inquisitoriais. Da mesma forma, deve-se colocar em dúvida o alcance e a validade desses registros enquanto "representativos" das histórias de vida de quem narra. Portanto, ainda que só se possa saber de Gabriel aquilo que está diretamente relacionado às suas dificuldades de escrita e leitura, pois é isso que ele conta e é isso que se registra, são significativamente importantes as demais informações que ele traz de forma espontânea durante a terapia: gostos; projetos de vida; desilusões; comentários diversos etc. As análises feitas aqui, com isso, levam em conta o conjunto dessas informações.

\section{"Eu tenho muita dificuldade de aprender": aprendizagem e envelhecimento social}

Atribuir uma "essência" é uma forma de dar sentido não apenas à narrativa, mas à própria vida. Nesse processo colabora uma outra série de informações que vão desde laudos médicos, avaliações pedagógicas, vocábulos e conceitos que se tornam de uso corrente em função de sua divulgação midiática, em jornais, revistas e televisão. Como se pode observar no trecho abaixo, esse "novo vocabulário" possibilitou a atribuição de um "nome": dislexia. Trata-se, portanto, de um "ato de nomeação" que é também um "ato de atribuição de uma essência" (BOURDIEU, 2008). Esse "ato de nomeação" demonstra que a construção de um sentido para sua história e para sua narrativa é social, e não individual como pode parecer. A 
representação que Gabriel pode fazer de si mesmo depende da representação social feita de suas dificuldades.

Essa "essencialização" corresponde também a uma "estigmatização", à atribuição de uma marca que define a forma como as demais pessoas interagem com a pessoa estigmatizada (GOFFMAN, 1982). E, em muitos casos, define a percepção que o estigmatizado faz das relações estabelecidas com ele pelas demais pessoas. Diferente de outras tantas marcas e estigmas, as dificuldades de leitura e escrita não são imediatamente visíveis, mas tornam-se visíveis em determinadas situações, o que faz com que as pessoas passem a ser, nos termos de Erving Goffman (1982), “desacreditáveis". Com isso, o estigmatizado, uma vez que foi revelada sua "marca", percebe as ações das demais pessoas sempre em função de seu "estigma", rejeitando-o, tratando-o de modo diferente, às vezes com maior "tolerância" como forma de aceitação de sua dificuldade. No caso de Gabriel, dispomos apenas da narrativa de sua percepção desse processo, em que os momentos mais dolorosos são, sem dúvida, aqueles em que suas dificuldades são reveladas:

P: Onde você percebe que essa dificuldade está atrapalhando tanto no seu trabalho quanto aqui na Universidade?

G: eu acho que é isso assim, sabe?, chega um ponto que você já fica tímido de fazer as coisas, você fica com vergonha... Se o professor falar assim "escreve agora para mim sobre tal coisa", eu não consigo, eu travo, se não me der o tema então...

Não por acaso, os momentos em que a manifestação de suas dificuldades se torna aparente para o outro, que precisa se dar por meio da linguagem escrita, são também aqueles que lhe causam maior sofrimento, tanto mais quanto maior é seu esforço de ascensão social. Nos verbos que usa ao se narrar, há sempre a presença de uma utilização passiva: "foi assim”, “aconteceu assim”, “foi por causa disso", “eu não sabia”. Ou seja, há sempre algo acima dele que o domina e que o faz sucumbir diante do inominável poder que ele não pode vencer, e por essa razão mantém-no mediano, permitindo-lhe não ficar inteiro.

A narrativa também demonstra sua dificuldade para estabelecer um projeto de vida e, até mesmo, para definir uma carreira profissional. Suas dificuldades são mais evidentes sempre que o contexto implica uma maior cobrança social, o que frustra suas expectativas de ascensão. Por outro lado, como ocupa um cargo de supervisão, pode transferir para os subalternos as tarefas que não consegue realizar.

Ainda que, em termos hierárquicos e estruturais, consiga compensar e até mesmo ocultar suas dificuldades em função do cargo que ocupa, a percepção que faz de si mesmo produz e legitima um processo permanente de "autoexclusão" social, de desistência ou 
abandono de projetos e compromissos: primeiro na escola; depois na Universidade; e no mercado de trabalho, como se toda sua trajetória tivesse sido abortada desde o início. A impossibilidade de êxito se mostra também no contexto familiar. Primeiro, tem dificuldade para transmitir uma "herança" às filhas, uma vez que não consegue acompanhar sua escolarização:

G: não quero ficar nessa vida, eu já tenho 42 anos já passou do tempo de procurar ajuda, e chega um tempo, claro com filhos e tal a gente quer melhorar de vida, a gente está estudando para passar em concurso para ir para a faculdade.

G: eu não sei bem o que vai ser do meu futuro e isso me preocupa muito. Tenho duas filhas e preciso ganhar o suficiente para pagar os estudos e os gastos que elas vão me dar. Preciso dar exemplos e mostrar o quanto o pai delas batalhou para deixar algo que na verdade é muito mais importante que dinheiro, que é o exemplo de ter um rumo certo na vida, de ter uma profissão. Espero que um dia eu possa ver que essa dificuldade de aprendizado foi superada e que tudo não passou de uma fase... meus sonhos já acredito não realizá-los, mas posso realizar o sonho das minhas filhas.

Segundo, sua dificuldade de aprendizagem, sua "marca", se traduz em dificuldade para definir uma trajetória de "envelhecimento social": não consegue conquistar uma situação de êxito no trabalho, como profissional (não conseguiu seguir uma carreira militar, a exemplo de seu pai), nem na família, como pai e marido. Não parece fortuito, portanto, que ele diga não conseguir se "lembrar" de como se escreve a palavra "sucesso". Dessa forma, a narrativa de dificuldade se transforma, gradativamente, em narrativa de "fracasso" em todas as esferas de sua vida:

G: Vivo um casamento estranho, como se fosse dois irmãos, mas só eu converso puxo assunto. Ela fala só quando a favorece e meus sonhos e ideias ficam sempre de lado. [...] Não tenho e nunca tive o apoio dela e nem sei se com a dificuldade de escrita, se devo voltar... não só a de escrita, mas de cálculos e tal... isso me frustra e me deixa com a autoestima muito baixa.

Em determinado momento do acompanhamento fonoaudiológico, em que a pesquisadora apresentou a música Roda Viva (BUARQUE, 1983) com o objetivo de desenvolver uma poesia (que será apresentada posteriormente), Gabriel sugeriu outras canções, afirmando que teriam maior afinidade com ele, referindo que até se emociona ao ouvi-las, pois suas letras condizem com sua trajetória de vida. Não por acaso as músicas de que mais gosta falam de solidão (no casamento, na vida) e do contínuo abandono. Na primeira delas, Mulher Maravilha (TINTO, et al., 2018), o amor da mulher amada está perdido e ele substitui por outro, do filho do casal. A mulher real se afasta e seu lugar é ocupado pela Mulher Maravilha, numa versão idealizada tanto da mulher, quanto da vida conjugal. Na 
segunda, Cavaleiro Solitário (GONZAGUINHA, 1993), ele pede perdão à mulher amada, deixa-a e segue seu caminho sozinho, sem ela, sem sua "cruz", que é deixada "vazia".

Essa impossibilidade de "envelhecimento social", de ocupar de forma satisfatória os papéis sociais (GOFFMAN, 1985) que caracterizam a vida adulta (pai, marido, profissional) se transforma em desejo de fuga para uma vida no campo na sua forma mais idealizada, livre de pressões e cobranças sociais. Não por acaso os animais, em sua narrativa, sempre aparecem como figuras de afeto, diferentemente das pessoas:

G: Eu sempre gostei muito de bicho, e aí minha vida sempre foi isso aí, gostar de bicho, sempre tive muito cachorro.

E, em outro momento da terapia, quando decide entregar uma breve narrativa escrita de sua vida e, portanto, de suas dificuldades e desilusões:

G: Sempre gostei da vida no campo [...] Ai conheci a Lúcia [nome fictício], minha esposa. Achei que por ela ser do interior do Paraná e falar que gostava dessa vida na roça, eu poderia retomar meus sonhos de infância e viver da terra. Que nada... mas [mais] uma vez meus sonhos vieram por agua abaixo. Passei por um processo estranho, sempre sonhei acordado com o campo, hoje sinto até uma tristeza e nem sei se gosto mais de sonhar.

A idealização do campo é frequente: a telenovela que mais gosta é Ana Raio e Zé Trovão (e o capítulo que mais gosta é aquele em que Zé Trovão deixa sua noiva para ficar com a mulher do campo, Ana Raio); e o poema que escreve durante a terapia também é sobre a vida idealizada no campo, sem filhos e sem as pressões do mercado de trabalho. Sem, portanto, qualquer situação que possa "revelar" sua "essência", sua "marca", seu "estigma": "PORVIR: Quero morar no campo / Em uma casinha / Com varanda e balanço / Bem escondidinha / Para com minhas filhas cantar / Ver as flores perfumadas / E os pássaros a voar / À noite ver o céu estrelado / E a lua a nos iluminar / A fogueira forma fagulhas / Que se confundem com os / Vagalumes a brilhar / Respirando o mais puro ar / Sigo minha vida a sonhar".

Mas até mesmo nesse contexto, da vida no campo, seu estigma se revela e, diante dele, os projetos de vida tornam-se uma impossibilidade:

G: Tenho muitas dificuldades de me concentrar e isso também é um problema... até coisas que eu gosto como cavalos, eu tento me concentrar, mas quando vejo já estou pensando em outras coisas. Tenho tantos livros que começo a ler e não termino, falta força de vontade e acredito que isso venha da dificuldade de concentração que trago desde pequeno. 
É possível intuir, a partir de sua fala, que a opinião do pai foi promotora da forma como Gabriel se construiu como pessoa e talvez tenha feito com ele estivesse sempre "atrasado" em seu desenvolvimento. A mãe que o acompanhava, que lia para ele, se perdeu no tempo. O pai, que o forçou a voltar no tempo, deixou-o parado lá naquele momento de ruptura, de onde ele não consegue mais sair. Na verdade, ele se mantém na $1^{\text {a }}$ série do Ensino Fundamental, como se estivesse repetindo eternamente esse ano escolar, sem conseguir se colocar na sociedade, sem se colocar em pé, com a letra feia, com dificuldades nas práticas de letramento, porque talvez a voz de seu pai esteja ainda o impedindo de avançar.

Esse fenômeno de fixidez discursiva, a que Maia-Vasconcelos (2003) chamou de hardness, compreende essa peculiaridade humana de se manter ligado a um trauma através e a despeito da temporalidade. Aspectos semelhantes de busca por esse "elo perdido" também são observados por Donida (2018), ao relatar que os universitários com dificuldades tendem a retomar em seu discurso elementos linguísticos que denotam o sofrimento com episódios escolares do passado infligidos no presente a partir das exigências universitárias. Assim, a Universidade retoma esse lugar de cobrança, em que os estudantes se veem incapacitados de progredir, solidificando o "não saber", em que o acadêmico "patina e leva tudo aos trancos e barrancos", "trava" e "bloqueia".

Através do exposto, como um estudo inicial que desfaz fronteiras historicamente delimitadas entre as áreas aqui articuladas, permite-se observar que um primeiro contato pouco atento à narrativa de dificuldades apresentada pelo estudante pode provocar deslegitimação do seu dizer e, com isso, da sua história de sofrimento, uma vez que suas dificuldades não se "caracterizam" como escopo de trabalho da Fonoaudiologia. Ou, além disso, poderiam sugerir uma alteração "patológica", ao se "nomear" a narrativa através de influências externas incorporadas ao seu discurso (mídia, professores, amigos etc.).

\section{Considerações Finais}

O presente trabalho buscou apresentar ao leitor um estudo de caso de um estudante universitário que procurou a clínica de fonoaudiologia e em cuja narrativa apresentou todos os sofrimentos e dificuldades que estiveram presentes em sua trajetória de vida. Ao buscar apoio em três áreas: Linguística; Fonoaudiologia; e Sociologia, objetivou-se compreender como a construção dessa narrativa foi possível e como ela se apresentou nesse contexto clínico. Reitera-se que, notadamente, as áreas convergem para uma mesma análise: a marcação dos aspectos sociais imbricados na construção de todo o percurso do estudante. 
As dificuldades em universitários ainda representam um campo pouco explorado, principalmente quando se trata de discutir o lugar social da clínica fonoaudiológica na compreensão e no acolhimento de estudantes. Ela desempenha um importante papel na confirmação, na caracterização e posterior remediação das dificuldades percebidas pelos estudantes que não conseguem se adequar às exigências universitárias. A reflexão acerca dos fatores que determinaram a busca pela clínica, em contraponto com outras ações educacionais, pode sinalizar para mudanças pedagógicas na instituição ou não, assim como práticas clínicas integradas e interdisciplinares.

Uma vez compreendida na forma de "essência", de "estigma", de "marca", a narrativa de dificuldades se amplia e se desdobra em tantas outras dificuldades, tanto profissionais quanto familiares, como se todas tivessem uma mesma e única causa. Mais uma vez, é importante notar que sua narrativa tem início no momento da alfabetização. O momento em que essa "marca" se revela para os outros é o momento em que se revela também para ele. Ou seja, a percepção de suas dificuldades está inteiramente alicerçada na percepção que ele acredita que as demais pessoas fazem dele. Impossível supor, portanto, que a percepção que ele tem de si mesmo seja tão somente "subjetiva". Ela é "objetiva" no sentido de que se alicerça em uma "construção social” de suas dificuldades e, com isso, de sua identidade. Os momentos mais dolorosos, portanto, são aqueles em que essa "marca" se revela, transformase em um "estigma", torna-se perceptível para as demais pessoas, para a sociedade, e assim se torna "objetiva", inegável.

É possível encontrar aí o que De Gaulejac (2009) encontrou em seu trabalho com os imigrantes. Esse sentir-se estrangeiro em sua terra natal - que pode ser o próprio corpo - é muito forte e produz uma imagem devastadora a um sujeito que já vem desde a infância sem ter consciência do que é ser no mundo. Repetir de ano tem uma representação muito negativa de jogar o futuro sempre para o passado. É como estar sempre caminhando para trás. Mas assim como a recente visibilidade dada às dificuldades de ensino e aprendizagem, seja pelas reformas educacionais, seja pela mídia, possibilitou-lhe "nomear" e atribuir uma essência a essas mesmas dificuldades, o contexto atual brasileiro também propicia que uma nova "essência" lhe seja atribuída.

As relações de gênero, tal como as constrói ao falar de seus pais, são as principais condicionantes de sua relação com a escola e com o trabalho. Por um lado, define um projeto de vida que o assemelha a seu pai e o afasta da escola, ou seja, da mãe. Mas, por outro, é o pai quem "revela" sua dificuldade, para ele e para os outros, fazendo com que essa cena constantemente se repita nos momentos em que está em jogo a possibilidade de melhora de 
sua vida, ou seja, sua chance de ascensão social. Quanto maior seu esforço para tentar essa ascensão, mais suas dificuldades ficam expostas, uma vez que as cobranças em relação à escrita e à leitura tornam-se mais exigentes.

A busca pela clínica fonoaudiológica, nesse contexto, não é realizada de modo aleatório pelo estudante: ela demarca um lugar que assume a possibilidade de ser responsável pela "coesão" da história de vida do estudante. Ao ter o "poder" de "nomear" essas dificuldades educacionais, que se prolongam para todos os outros aspectos de sua vida, a clínica emerge como o lugar de apoio e acolhimento que ações educacionais realizadas pela instituição ou aulas particulares para minimizar os déficits alfabetizacionais não poderiam fazer, corroborando com a sua negação em participar das oficinas de práticas de letramentos em grupo. Distintamente da psicoterapia, a busca pela Fonoaudiologia também tem o sentido de não provocar a mudança no que é experienciado em sua trajetória: a dificuldade lhe é externa e há uma força que o faz "travar", culpada por todos os entraves em sua vida. Por ela lhe ser "externa", não pode ser passível de "conserto" interno.

É a partir do exposto que se espera que outros trabalhos futuros possam explorar os fatores que levam universitários a procurar a clínica para trabalhar suas dificuldades acadêmicas, enquanto anulam a possibilidade de apoio de ações educacionais institucionais. Nesse sentido, as instituições de ensino podem se beneficiar ao explorar esses aspectos e, juntamente com um trabalho integrado de várias áreas do conhecimento, transformar as ações de apoio pedagógico.

\section{REFERÊNCIAS}

BAKHTIN, M. M. Estética da criação verbal. São Paulo: Martins Fontes, 2003.

BAKHTIN, M. M; VOLOSHÍNOV, V. N. Marxismo e filosofia da linguagem: problemas fundamentais do método sociológico da linguagem. 16. ed. São Paulo: Hucitec, 2014.

BOURDIEU, P. A economia das trocas linguísticas: O que falar quer dizer. 2. ed. 1. reimp. São Paulo: Editora da Universidade de São Paulo, 2008.

BRUNER, J. S. Atos de significação. Porto Alegre: Artes Médicas, 1997.

BUARQUE, C. Roda Viva. Álbum: Chico Buarque de Hollanda - Volume 3. Data de lançamento: 1968.

BURKE, P. Cultura popular na idade moderna: Europa, 1500-1800. São Paulo: Companhia das Letras, 1995. 
CAPONI, S. La psiquiatrización de la vida cotidiana: el DSM y sus dificultades.

Metatheoria, Buenos Aires, v. 8, n. 2, 2018. Disponível em:

http://www.metatheoria.com.ar/index.php/m/article/view/179. Acesso em: 17 abr. 2020.

COLlARES, C. A. L.; MOYSÉS, M. A. A.; RIBEIRO, M. C. F. (Org.). Novas capturas, antigos diagnósticos da era dos transtornos. Campinas: Mercado de Letras, 2013.

COLOMBANI, F.; CARÁCIO, F. C. C.; VERÍSSIMO, D. M. M. A medicalização e sua história: normalização e disciplinamento da infância por meio da escola. Revista IberoAmericana de Estudos em Educação, Araraquara, v. 14, n. 4, p. 2057-2070, 2019. Disponível em: https://periodicos.fclar.unesp.br/iberoamericana/article/view/12929/8697. Acesso em: 17 abr. 2020.

DE GAULEJAC, V. Qui est "Je"? Sociologie du clinique. Paris: Seuil, 2009.

DONIDA, L. O. Universitários com dificuldade de leitura e escrita: Desvelando Discursos. 2018. 145 f. Dissertação (Mestrado em Linguística) - Universidade Federal de Santa Catarina, Florianópolis, 2018. Disponível em:

https://repositorio.ufsc.br/bitstream/handle/123456789/194394/PLLG0731-D.pdf?sequence=1\&amp;isAllowed=y. Acesso em: 2 mar. 2020.

ELIASSEN, E. S. A discursivização do diagnóstico da dislexia: da teoria à prática. 2018. 224 f. Dissertação (Mestrado em Linguística) - Universidade Federal de Santa Catarina, Florianópolis, 2018. Disponível em: https://docero.com.br/doc/v1csns. Acesso em: 19 mar. 2019.

FREIRE, P. Educação como prática da liberdade. Rio de Janeiro: Paz e Terra, 1977.

GIROTO, C. R. M.; ARAUJO, L. A.; VITTA, F. C. F. Discursivização sobre "doenças do não aprender" no contexto educacional inclusivo: o que dizem os professores de educação infantil? Revista Ibero-Americana de Estudos em Educação, Araraquara, v. 14, n. 1, p. 807-825, 2019. Disponível em:

https://periodicos.fclar.unesp.br/iberoamericana/article/view/12208/8058. Acesso em: 17 abr. 2020.

GOFFMAN, E. Estigma: notas sobre a manipulação da identidade deteriorada. Rio de Janeiro: Zahar, 1982.

GOFFMAN, E. A representação do eu na vida cotidiana. Petrópolis: Vozes, 1985.

GONZAGUINHA (nome artístico). Luiz Gonzaga do Nascimento Júnior. Cavaleiro Solitário. Álbum: Cavaleiro Solitário. Gravadora: Som Livre, 1993.

LAHIRE, B. Homem plural: os determinantes da ação. Petrópolis: Vozes, 2002.

MICELI, S. Intelectuais à brasileira. São Paulo, Companhia das Letras, 2001.

MAIA-VASCONCELOS, S. Penser l'école et la construction des savoirs: une étude menée auprès d'adolescents cancéreux. 2003. 500 f. Tese (Doutorado em Sciences de l'Éducation) Université de Nantes, Nantes (França), 2003. 
MAIA-VASCONCELOS, S. Clínica do discurso: a arte da escuta. Fortaleza: Premius, 2005.

MAIA-VASCONCELOS, S.; VASCONCELOS, F. P.; TAVARES, M. L.; REBOUÇAS, R. B. M. Estudo semiótico da paisagem: as histórias dos moradores da praia do Titãzinho (Fortaleza/CE). Intersecções, Jundiaí, v. 3, p. 154-169, 2013. Disponível em: http://www.repositorio.ufc.br/handle/riufc/18210. Acesso em: 20 abr. 2020.

ROSA, J. G. Grande sertão: veredas. Rio de Janeiro: Nova Fronteira, 2006.

SANTANA, A. P.; SANTOS, K. P. A perspectiva enunciativo-discursiva de Bakhtin e a análise da linguagem na clínica fonoaudiológica. Bakhtiniana, Revista de Estudos do Discurso, São Paulo, v. 12, n. 2, p. 174-190, maio 2017. Disponível em: https://revistas.pucsp.br/bakhtiniana/article/view/27941. Acesso em: 17 mar. 2020.

ROSENTHAL, G. História de vida vivenciada e história de vida narrada: A interrelação entre experiência, recordar e narrar. Civitas - Revista de Ciências Sociais, Porto Alegre, v. 14, n. 2, p. 227-249, jun. 2014. Disponível em:

http://revistaseletronicas.pucrs.br/ojs/index.php/civitas/article/view/17116. Acesso em: 16 abr. 2020.

ROUSSEAU, J. Émile ou de l’éducation. Paris: Garnier-Flamarion, 1966.

SIGNOR, R. C. F.; BERBERIAN, A. P.; SANTANA, A. P. A medicalização da educação: implicações para a constituição do sujeito/aprendiz. Educ. Pesqui., São Paulo, v. 43, n. 3, p. 743-763, 2017. Disponível em:

http://www.scielo.br/scielo.php?script=sci_arttext\&pid=S1517-

97022017000300743\&lng=en\&nrm=iso. Acesso em: 17 abr. 2020.

TINTO, F.; MARX, N.; MELLO, D.; HUGO, V.; PANCADINHA, P.; CAMARGO, D.; MENEZESR. Mulher Maravilha. Lançado por João Neto e Frederico. Data de lançamento: 2018.

VASCONCELOS, S. M. F.; CARDOSO, M. N. F. Novas fronteiras linguísticas: um estudo sobre o gênero autobiográfico. Revista Eutomia, Recife, v. 1, n. 3, p. 652-664, jul. 2009. Disponível em:

http://www.repositorio.ufc.br/bitstream/riufc/26446/1/2009_art_sfmvasconcelos.pdf. Acesso em: 14 abr. 2020. 


\section{Como referenciar este artigo}

DONIDA, L. O.; BERGAMO, A.; MAIA-VASCONCELOS, S. "Sempre fui meio termo": A clínica fonoaudiológica e a construção de narrativas no contexto da Educação Superior. Revista Ibero-Americana de Estudos em Educação, Araraquara, v. 15, n. esp. 5, p. 30013019, dez. 2020. e-ISSN: 1982-5587. DOI: https://doi.org/10.21723/riaee.v15iesp5.14571

Submetido em: 10/01/2020

Revisões requeridas em: 25/05/2020

Aprovado em: $30 / 10 / 2020$

Publicado em: 01/12/2020 